\title{
Negative Social Cognitions in Socially Anxious Youth: Distorted Reality or a Kernel of Truth?
}

\author{
Anne C. Miers • Anke W. Blöte • \\ P. Michiel Westenberg
}

Published online: 2 October 2010

(C) The Author(s) 2010. This article is published with open access at Springerlink.com

\begin{abstract}
We review studies that investigate negative social cognitions of socially anxious youth in relation to two specific domains: interpretation of ambiguous social situations and self-evaluation of social performance, including social skills and nervous behaviors. In this review, we address the question whether socially anxious youth's negative perceptions are distortions of reality or reflect a kernel of truth as compared to other sources of information including independent adult observers and age peers. Studies key to this question are those that investigate not only the social perceptions themselves but also the social behavior of socially anxious youth. Hence the selection of studies for the review was based on this criterion. From the relevant literature it is, as yet, unclear whether the negative interpretations of ambiguous social situations shown by socially anxious youth are distorted or a reflection of reality. Socially anxious youth's selfevaluations of social skills appear partly distorted and partly true, depending on the person judging the social skills. In contrast, self-evaluations of nervous behaviors appear distorted. The studies reviewed indicate that research would benefit from including a wider range of perceptions from persons relevant to the socially anxious youth's daily social environment, not only parents and teachers but also their age peers.
\end{abstract}

Keywords Socially anxious youth - Negative cognitions . Interpretation bias · Social skills $\cdot$ Nervousness

\footnotetext{
A. C. Miers $(\square)$ · A. W. Blöte · P. M. Westenberg Institute of Psychology, Unit Developmental and Educational Psychology, Leiden University, P. O. Box 9555,

2300 RB Leiden, The Netherlands

e-mail: acmiers@fsw.leidenuniv.nl
}

\section{Introduction}

Since the introduction of two cognitive-behavioral models of social anxiety in the 1990s (Clark and Wells 1995; Rapee and Heimberg 1997), a proliferation of studies have focused on the cognitive aspects of social anxiety as described in these models (Schultz and Heimberg 2008). The cognitive-behavioral models describe what happens to an individual during, or in anticipation of, a socially threatening situation, in terms of cognitive, behavioral and physical processes (Clark and Wells 1995; Rapee and Heimberg 1997). Clark and Wells (1995) primarily focus on socially anxious individuals' beliefs about the danger inherent in social situations and the processes that prevent them from changing their beliefs and ultimately, reducing their social anxiety. The core feature of Rapee and Heimberg's (1997) model is the mental representation formed by the individual of his/her external appearance and behavior as seen by the audience. This mental representation is compared with the individual's perception of the audience's standard for evaluation. The extent to which the mental representation of performance does not meet the audience's perceived standards determines the likelihood of negative evaluation and experience of anxiety.

Of key importance in the context of the studies reviewed in this article is the way in which the cognitive models describe how socially anxious persons tend to engage in distorted processing of information related to a socialevaluative situation. Because socially anxious individuals are greatly concerned about the possibility of negative evaluation from others (Clark and Wells 1995) and assume that other people are inherently critical (Rapee and Heimberg 1997), they take a negative view of social situations and the accompanying behavioral, cognitive and somatic responses within themselves. The assumption that socially anxious 
persons' negative view is a distortion of reality underpins the treatment approach of Cognitive Behavioral Therapy (CBT) as one of the main principles of CBT is to try to alter the individual's negative perceptions of social situations.

In the present review, the tendency toward a negative perspective of social situations is investigated in two domains. These domains are (a) interpretation of ambiguous social situations and (b) self-evaluation of social skills and nervous behaviors (see Fig. 1). This review also aims to ascertain the extent to which socially anxious persons' negative perspective is justified; this is addressed in the cognitive models but is not discussed extensively (Clark and Wells 1995; Rapee and Heimberg 1997). Do socially anxious individuals have good reason for their negative perceptions, that is, is there a kernel of truth in their negative social cognitions? Or, are their perceptions a distortion of reality and their thoughts negatively biased? This review focuses mainly on studies that investigated youth samples because a key feature of social anxiety, fear of negative evaluation, increases in the adolescent period (e.g., Weems and Costa 2005; Westenberg et al. 2004) and the clinical manifestation of social anxiety, social phobia, typically has its onset in early to mid adolescence (Rapee and Spence 2004). We organize the review around studies recently conducted in our laboratory and also draw from a sample of studies in the extant literature.

In sum, the current review aims to address the following research questions in socially anxious youth:

1. Is there evidence for negative perceptions in relation to interpretation of ambiguous social situations and selfevaluation of social performance?

2. Are the negative perceptions actually justified by sources of information other than socially anxious youth themselves, such as independent observers and fellow age peers? Or are the negative perceptions of socially anxious youth really unwarranted as based on these other sources of information?

In this review we will first present studies that investigated negative social cognitions in the two domains previously described with a particular focus on studies that employed youth samples. Following this we will discuss the findings in relation to the two research questions. Finally, we will close the article with clinical and theoretical implications of the reviewed studies and suggestions for future research.

\section{Negatively Biased Interpretations of Social Situations}

The two leading cognitive models assume that socially anxious persons interpret social situations in a threatening way and that their interpretations are more negative than non-socially anxious persons' interpretations (Clark and Wells 1995; Rapee and Heimberg 1997). For example, imagine a person has just given a speech in front of a large audience and at the end of the speech nobody in the audience asks a question. How would the speaker interpret this? For a person without strong socially anxious feelings the lack of questions is likely to be interpreted in a positive or neutral manner. For example, that the speech was very clear, or due to the speech taking place at the end of the day all audience members were too tired to ask a question. However, for a socially anxious person it is likely that the lack of questions would be interpreted as meaning that something was wrong with their speech; it was unclear, or difficult to follow. This tendency to place a negative meaning on an ambiguous
Fig. 1 Socially anxious individuals' perceptions and negative bias in social situations in relation to the evaluation of their behavior by others. Representation of the main variables (rectangular boxes) and measures (ovals) discussed in the paper

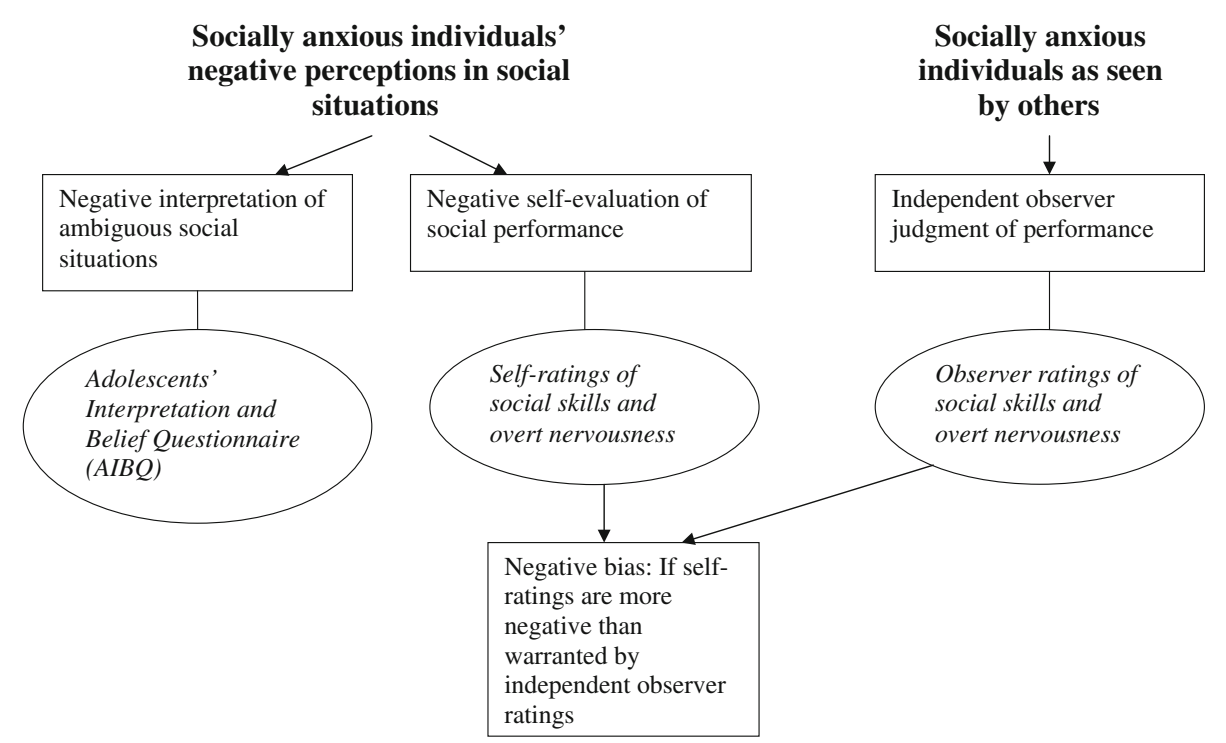


social cue is called an interpretation bias (Heinrichs and Hofmann 2001).

Highly anxious children and adolescents interpret ambiguous situations as more threatening (negative) than non anxious peers (e.g., Barrett et al. 1996; Bögels and Zigterman 2000; Bögels et al. 2003; Creswell et al. 2005; Chorpita et al. 1996; Micco and Ehrenreich 2008; Muris et al. 2000, 2003). However, the studies that specifically addressed interpretation bias in socially anxious youth are scarce (see also Muris 2010).

In one study, Bögels et al. (2003) compared children's (aged 7-12 years) interpretations of different situations, reflecting social, separation and generalized anxiety, and using a generalized anxious, social phobic and separation anxious group. Children in the social phobia group made significantly more negative interpretations of social situations and significantly fewer negative interpretations of separation stories compared to the separation anxiety group. No differences were found between the three anxiety groups on the generalized stories. Thus, the socially phobic group's interpretations were partly specific to social situations and partly more general in nature.

Vassilopoulos and Banerjee (2008) evaluated cognitive biases in a sample of 11-13 year old children who were presented with descriptions of positive and mildly negative social situations. These authors found a significant positive relationship between social anxiety level and the tendency to interpret negative social events in a catastrophic fashion. This relationship held after controlling for children's level of self-reported depression as measured by the short form of the Children's Depression Inventory (CDI; Kovacs 1992). Social anxiety was not related to interpretations of positive social situations.

In a training study, Vassilopoulos et al. (2009) presented 10-11 year old high socially anxious children with descriptions of social situations together with a negative and a benign interpretation of that situation. After the children had indicated which interpretation was describing how they would think in that situation, they were given feedback on what was the "correct" interpretation. A control group did not receive this training. It was found that the training not only reduced the negative interpretations of the children in the experimental group, but also reduced their social anxiety.

In a study by Miers et al. (2008) the presence of an interpretation bias was tested in a non-clinical adolescent sample and a number of issues central to the study of this bias using self-report methods were investigated. These issues were derived from the main findings in the adult literature and concern the following: (a) whether the interpretation bias reflects a real propensity to favor negative explanations for ambiguous social situations over positive ones, or, whether it reflects a lack of positive explanations (Amir et al. 1998; Constans et al. 1999; Huppert et al. 2003; Stopa and Clark 2000). That is, are positive explanations absent or are they given less importance than negative interpretations in the minds of socially anxious adolescents? (b) whether a socially anxious person's belief in a particular interpretation is as important as the likelihood of the interpretation coming to mind (Clark et al. 1997); (c) the specificity of interpretation bias to social anxiety. Some research has shown that negative interpretations of social situations are also characteristic of individuals with depression (e.g., Franklin et al. 2005). Is interpretation bias particular to social anxiety or is it a feature of an underlying negative affect common to anxiety and depression? And (d) the content-specificity of interpretation bias; do socially anxious individuals show an interpretation bias only in social situations or is it also present in non-social situations?

Miers et al. (2008) developed the Adolescents' Interpretation and Belief Questionnaire (AIBQ) to measure interpretation bias. The AIBQ required participants to indicate how likely it is that a particular interpretation for an ambiguous social or non-social situation would pop up in their mind. The AIBQ was modeled on two self-report instruments used in the adult literature (Stopa and Clark 2000; Voncken et al. 2003). Three different interpretations of each ambiguous situation, a positive, a neutral and a negative one were rated separately on a five point Likert scale according to the likelihood that the interpretation would pop up in the participant's mind. Second, participants had to choose which of the three interpretations they believed to be the most correct with a higher score indicating belief in a more negative interpretation. In line with the authors' expectations, socially anxious adolescents rated negative interpretations of social situations as more likely to come to mind than adolescents with moderate social anxiety. The socially anxious group was also more likely to believe the negative interpretation for social situations as compared to the moderate social anxiety group (Miers et al. 2008). However, the effect for negative interpretations coming to mind was stronger than for belief in the negative interpretation. This prompted Miers et al. to suggest that the strength of belief in a negative interpretation is less important than the likelihood of that interpretation coming to mind, at least for adolescent social anxiety. To the best of our knowledge, no other study has examined this issue in socially anxious youth; hence we cannot as yet draw firm conclusions.

In relation to the first issue, Miers et al. (2008) showed that socially anxious adolescents are more likely to make negative interpretations of social situations but are not less likely to have positive interpretations of these situations. Similarly, Vassilopoulos and Banerjee (2008) found support for the presence of a negative bias rather than the 
absence of positive interpretations in their sample; however their measurement of interpretation bias was slightly different. Children rated how likely a neutral explanation would come to mind in response to a mildly negative social event. Because of the nature of mildly negative events, positive interpretations would not be plausible; hence neutral interpretations are a suitable comparison to the positive explanations in the AIBQ. The weak and nonsignificant correlation between neutral interpretations of negative events and social anxiety reported by Vassilopoulos and Banerjee (2008) corroborates the findings of Miers et al. (2008) that socially anxious children are as likely as non-anxious children to interpret ambiguous social events in a neutral way.

To address the third issue Miers et al. (2008) measured negative affect using the Positive and Negative Affect Scale (PANAS; Watson et al. 1988). After controlling for levels of negative affect the differences between high socially anxious and moderate anxious youth on negative interpretations coming to mind and belief in negative interpretations of social situations remained (Miers et al. 2008). This indicates that the negative interpretations are not a consequence of a general negative affect factor associated with other emotional disorders, such as depression. In the adult literature the tendency to interpret ambiguous social situations negatively has frequently been shown to be specific to social anxiety, rather than a feature of negative affect associated with anxiety and depression (Amir et al. 2005; Constans et al. 1999; Huppert et al. 2003, 2007; Voncken et al. 2007). In these studies depression (Huppert et al. 2003, 2007) or negative affect (Constans et al. 1999) were either measured using selfreport instruments or groups of socially anxious, nonanxious and depressed persons were compared in clinical (Voncken et al. 2007) or non-clinical samples (Amir et al. 2005). Hence, the pattern of findings presented in Miers et al. (2008) and in the study of Vassilopoulos and Banerjee (2008) for youth samples converge with those from studies with adult samples and indicate that interpretation bias is particular to social anxiety.

In terms of the fourth issue, Miers et al. (2008) also found evidence for content-specificity of interpretation bias. The interpretation bias appeared to be specific for social situations. Thus, socially anxious adolescents were not more likely than their non-anxious peers to rate negative explanations of non-social situations as coming to mind, after statistically accounting for negative affect levels. Content specificity has been widely studied in adult populations and the findings suggest that the interpretation bias is indeed specific to social situations and does not extend to non-social situations (Amir et al. 2005; Constans et al. 1999; Huppert et al. 2003; Voncken et al. 2003, 2007; Wilson and Rapee 2005).
In general, these findings paint a pretty dim picture of the way in which youth with high levels of social anxiety interpret ambiguous cues in social situations, particularly as social situations are generally full of ambiguities. This would make daily life quite distressing for socially anxious youth if they indeed perceive negative reasons for unclear behavior toward them. In the interpretation bias literature it is assumed that a bias is present when socially anxious persons' perceptions diverge from those of individuals with low to moderate social anxiety. However, this comparison does not really provide enough information to decide whether the negative perceptions are indeed distortions of reality or grounded in actual negative experiences in social situations. Socially anxious youth might perceive social cues in a negative manner simply because they are socially inadequate and, as a result, receive negative feedback from others. Hence, to determine whether or not their negative perceptions in relation to interpretation of ambiguous social situations are based on a kernel of truth, actual social behavior and interpersonal relations should be measured (Vassilopoulos and Banerjee 2008). In the following section, we describe the predominant theoretical perspective on socially anxious individuals' negative cognitions of social performance before reviewing the results of studies that measured actual social behavior.

\section{Negatively Biased Self-Evaluations of Performance}

The cognitive models assume that socially anxious individuals evaluate their performance in social situations more negatively than persons without social anxiety (Clark and Wells 1995; Rapee and Heimberg 1997). In addition, the models also raise the question whether socially anxious persons' tendency to be more negative about their performance is warranted; do socially anxious persons really perform more poorly than their non-anxious counterparts in different social situations? Clark and Wells (1995) state that the negative performance thoughts are "partly distorted" (p. 81). Similarly, Rapee and Heimberg (1997) propose that the negative mental representation of socially anxious persons could be a result of "actual deficits", "distorted perceptions" or both (p. 745). Thus, these authors propose that although socially anxious persons are likely to overestimate how poor their performance is, there is still some degree of truth in their evaluations.

Studies measuring actual social behavior of socially anxious youth tend to differentiate between two components of social performance, actual social skills and overt nervousness (e.g., Inderbitzen-Nolan et al. 2007). Some studies report findings that are consistent with the social skills deficit hypothesis, that is, the negative evaluations of social performance are based on a social skills deficiency 
and therefore reflect a kernel of truth (e.g., Alfano et al. 2008; Inderbitzen-Nolan et al. 2007; Spence et al. 1999). However, other studies with youth samples do not find social skills differences between high and low socially anxious groups (e.g., Cartwright-Hatton et al. 2003, 2005; Erath et al. 2007). As regards evaluations of nervousness, studies show that socially anxious youth overestimate how nervous they appear during a social-evaluative task (Cartwright-Hatton et al. 2005; Inderbitzen-Nolan et al. 2007). Hence, socially anxious youth's ratings of nervousness appear to be a distortion of reality, as compared to the evaluations of independent observers. However, the findings concerning whether evaluations of social skills are distorted or a reflection of reality appear to be mixed.

In a study described in Miers et al. (2009) a possible explanation for the inconsistent findings was investigated. Miers et al. (2009) proposed that negatively biased selfevaluations of social performance are related to performance level. Performance level, as judged by independent observers, may vary among socially anxious individuals. Two studies have shown that, according to independent observers, some socially anxious individuals perform well in social situations whilst others have a poorer social performance (Morgan and Banerjee 2006; Rodebaugh and Rapee 2005). If a socially anxious individual's performance level is judged as poor their negative selfevaluations are likely to be more or less correct. However, if a socially anxious individual's performance level is good, the negative self-evaluations are likely to be incorrect and biased.

Miers et al. (2009) investigated social performance evaluations in a group of high socially anxious youth (versus low socially anxious youth, aged 9-17 years), differentiating between the two aspects of social performance, social skills and overt nervousness. The anxiety groups were selected according to self-reported scores on the Social Anxiety Scale for Adolescents (SAS-A; La Greca and Lopez 1998) with the high anxious group scoring $>1$ SD above the mean. Selection of the low anxious group began with scores in the second decile and continued until the same number of boys and girls were included as in the high anxious group. High and low socially anxious youth evaluated how well they performed during a short speech. Audio-visual recordings of the speeches were made and shown to independent observers (i.e., blind to anxiety group membership) who also evaluated the performances using the same questionnaire as participants. Miers et al. (2009) found that high socially anxious youth evaluated their performance in the Leiden Public Speaking Task (Leiden-PST; Westenberg et al. 2009) as significantly poorer than low socially anxious youth. However, Miers et al. (2009) also found that, according to independent observers the high anxious youth did not appear more nervous, stutter more or show more physical signs of nervousness such as blushing. Thus, it seems that for nervousness, high anxious youth's negative perceptions were distorted and were not matched by the other information source: adult observers. This is in line with current literature (e.g., Alden and Wallace 1995; Cartwright-Hatton et al. 2005; Norton and Hope 2001) and the cognitive models of social phobia in which concern about anxiety symptoms is prominent for socially anxious persons. Moreover, in that study self-evaluations of nervousness were not related to performance level; all high socially anxious youth had negatively biased perceptions regardless of how well they were judged to perform (Miers et al. 2009).

The findings in Miers et al. (2009) revealed a different pattern as regards the perception of social skills. Participants and independent observers were in agreement about the poorer social skills of high anxious youth. This suggested that the perceptions of the high socially anxious group were not biased. After teasing apart the good performing from the poor performing youth in order to examine the relation with performance level, the authors showed that the self-perceptions were justified only for some socially anxious youth, namely the poor performers. Those high anxious youth who were judged as performing relatively poorly had reasonably accurate self-evaluations of social skills. However, the good performing high anxious youth evaluated their skills as poorly as the poor performers; hence their perceptions were unwarranted and distorted. This finding is in line with results from studies investigating the effectiveness of video feedback on selfevaluations (Morgan and Banerjee 2006; Rodebaugh and Rapee 2005). In these studies, video feedback improved the self-evaluations of only the skilled participants (Morgan and Banerjee 2006) or the participants with larger underestimations of performance (Rodebaugh and Rapee 2005). Hence, the findings are consistent with the notion that a bias in relation to self-evaluations of social skills exists for some, but not all, socially anxious individuals.

The cognitive models of social phobia give an indication as to the origin of these negative social performance evaluations. They state that prior social experience influences the socially anxious person's beliefs about the social world (Clark and Wells 1995) or their mental representation in a social situation (Rapee and Heimberg 1997). Hence, it is very likely that the negative self-evaluations of socially anxious youth reflect unsuccessful social interactions with peers. A number of studies using a range of methodologies, including observations in the school environment (Blöte et al. 2007; Spence et al. 1999), sociometric nomination (Gazelle and Ladd 2003; Greco and Morris 2005) and peer liking conducted in the laboratory (Verduin and Kendall 2008) clearly show that socially anxious youth receive negative feedback, are disliked and neglected by 
their peer group. The literature to date therefore suggests that socially anxious youth have good reason to think about their social performance in a negative way.

A study described by Miers et al. (2010) explores whether unfamiliar same age peers perceive the social skills of socially anxious youth as poorer than the skills of their non-anxious counterparts. Using same age peers as observers of social skills instead of adults is considered important because peers might be more sensitive to slight digressions in the behavior of other youth. Furthermore, peer relations take on increasing dominance and importance in the adolescent period (e.g., Brown 2004; Hartup 1996) suggesting that evaluations from peers might be more relevant to the child's developing awareness of social self-worth. If socially anxious youth are perceived as lacking in social skills this might be a reason for their poor treatment, and in turn, their negative self-evaluations.

In Miers et al. (2010) a group of high $(n=20)$ and low $(n=20)$ socially anxious adolescents (age range 13-17 years) who took part in the Leiden-PST (Westenberg et al. 2009) were rated on their social skills by adolescents unknown to them. Miers et al. (2010) specifically chose unfamiliar age peers as raters in order to remove the influence of a child's longstanding social reputation in a peer group on reactions to that child's behavior (Verduin and Kendall 2008). A minimum of 20 peer raters per high or low anxious speaker was included and these peers rated the speakers in their own school classrooms. This approach was chosen in order to reflect an average reaction from a group within a normal school classroom situation. Peer raters were of a comparable age to the high and low anxious speakers and attended the same education levels. The speech recordings of high and low socially anxious adolescents were rated on four social skills: clarity of speech content, use of facial expressions, posture and body movement and way of speaking. These four skills capture the most important verbal and nonverbal behaviors of a speech performance and have been shown to differentiate socially anxious from nonanxious adults (Baker and Edelmann 2002).

The Miers et al. (2010) study reported large, significant differences between high and low socially anxious speakers: unfamiliar peers evaluated high anxious speakers as giving a poorer speech in terms of content, facial expressions, posture, and way of speaking. Furthermore, for all skills except facial expressions, the anxiety group difference could not be accounted for by high levels of depression in the high socially anxious group. These results are consistent with previous studies that revealed more negative treatment of socially anxious as compared to non-anxious children and adolescents in the school environment (Blöte et al. 2007; Spence et al. 1999) and greater disliking of children with social anxiety disorder than those without as rated by unfamiliar age peers (Verduin and Kendall 2008).
In the context of peer relations, then, high socially anxious youth's negative self-evaluations of social skills might in fact be justified and accurate. It is possible that, as a result of their inadequate social skills as perceived by peers, these peers react in a different, less pleasant manner towards them as compared with low anxious youth. This differential treatment is in turn noticed by the socially anxious youth, who may then come to expect negative outcomes from all types of social situations as a result of this repeated exposure to unpleasant social interactions. This brings us back to the interpretation bias. Perhaps this bias is underpinned by high anxious youth's exposure to negative outcomes from social relations with peers and should therefore be seen as based on truth, rather than a distortion of reality.

\section{Conclusions}

This review began with two research questions. The first question asked whether there is evidence for negative perceptions in relation to interpretation of ambiguous social situations and self-evaluation of social performance in socially anxious youth. To sum up the findings reviewed here with respect to the first research question, it appears that during social situations, socially anxious youth do have negative perceptions in relation to, respectively, the interpretation of ambiguous situations (Miers et al. 2008; Vassilopoulos and Banerjee 2008) and self-evaluation of performance (Cartwright-Hatton et al. 2005; InderbitzenNolan et al. 2007; Miers et al. 2009). The second research question asked whether these negative perceptions are justified by sources of information other than the socially anxious youth themselves, such as independent observers and fellow age peers. In terms of this second question the studies here reviewed suggest different answers for the different perceptions.

In relation to the negative interpretation bias we can only speculate that socially anxious youth's negative interpretations of ambiguous social cues are at least partly based on a kernel of truth, due to their experience of poor peer interactions (e.g., Blöte et al. 2007; Spence et al. 1999). However, because the reviewed studies did not disentangle the process of receiving negative feedback from one's social environment from the development of negative interpretations we do not know whether one precedes the other and hence to what extent the negative interpretations are distorted. As regards self-evaluations of how nervous one appears during a social-evaluative task the findings overall are in support of biased processing of nervousness. This is evident from the overestimations of the visibility of anxiety related symptoms and behaviors as compared to independent observers' evaluations 
(Cartwright-Hatton et al. 2005; Miers et al. 2009). For selfevaluations of social skills the findings indicate at least a partial justification for the low self-evaluations of socially anxious youth, as compared to adult observers (Miers et al. 2009); and a suggestion of wholly warranted low perceptions, as compared to peer observers (Miers et al. 2010).

\section{Clinical Implications}

The studies reviewed in this article may be used to inform treatment of youth with clinical levels of social anxiety. Before attempting to modify an interpretation bias it would seem important to first identify the quality of socially anxious youth's peer relations and possible reasons for peer rejection. It might be fruitless to modify the interpretation bias without increasing the chance that the socially anxious youth receives positive feedback from others. In the context of continuing poor peer relations it is unlikely that the interpretation bias could really be altered. Peer-perceived social skills deficits of socially anxious youth may be the reason for previously observed negative treatment and disliking (Blöte et al. 2007; Spence et al. 1999; Verduin and Kendall 2008). The present article is unable to definitively make this conclusion; however it is quite plausible that less adequate social skills are at least one aspect of high socially anxious youth's behavior that elicits negative responses from their peers (Verduin and Kendall 2008). Schneider (2009) showed that the behavior of socially withdrawn 10-12 year olds in trusted close friendships is characterized by unassertiveness, passivity and uncommunicativeness. Whether it is a lack of specific skills or a general reticent nature that hinders the prolongation of successful peer relations, it is clear that the behavior of socially anxious youth makes this group a target for peer exclusion. With this in mind, assertiveness training, targeted improvement of particular social skills or even attention to general appearance may all contribute to forming more constructive and positive social relationships.

In terms of negative perceptions of social performance, as suggested by the studies of Miers et al. (2009), Morgan and Banerjee (2006), and Rodebaugh and Rapee (2005) a "one size fits all" technique to correcting social skills evaluations might not be appropriate. Socially anxious youth who perform poorly are not likely to benefit from video feedback or cognitive strategies to correct their negative perceptions. A behavioral component would be preferable for these individuals in order to improve their social skills, followed by the cognitive method if required. For those evaluated as good performers, video feedback could be a key component of treatment. In addition, the study by Miers et al. (2010) advocates including the perceptions of age peers to inform the treatment of socially anxious youth's social skills. Improving social skills in a manner that elicits positive feedback from age peers, rather than adults, might be more effective at breaking the cycle of ineffective social interactions, expectations of negative social outcomes and fear of negative evaluation.

The other side of the social performance coin is nervousness: the visibility of one's anxious behaviors (e.g., stuttering, blushing). A number of studies (e.g., Cartwright-Hatton et al. 2005; Miers et al. 2009) imply that all socially anxious youth would benefit from being made aware that their anxious behaviors in a social-evaluative event are normal and are not more visible than the anxious behaviors of their non-anxious peers. Moreover, it would be important for therapists to emphasize that visible nervousness does not detrimentally affect other people's impressions of social performance (Blöte et al. 2009; Verduin and Kendall 2008; Voncken et al. 2006).

\section{Theoretical Implications and Recommendations for Future Research}

The findings reviewed in this article and those from several other studies (e.g., Siegel et al. 2009; Spence et al. 1999; Verduin and Kendall 2008) suggest that the theories of Clark and Wells (1995) and Rapee and Heimberg (1997) could be expanded into development models whereby the role of peer relations and interactions on the development of children and adolescents' negative social perceptions is included. The theories do offer a starting point for this extension. For example, Clark and Wells (1995) refer to "previous experience" interacting with innate behavioral predispositions as key to the development of social phobics' negative assumptions of the social world. Similarly, Rapee and Heimberg (1997) state that prior experience and feedback in a social situation is one source of information that is used to develop the mental representation of the self in social situations. The "experience" referred to in both models should incorporate social interactions with age peers, particularly in adolescence, as this period is associated with both an increase in the importance of peers to emotional development (La Greca and Prinstein 1999), and fears for social-evaluative situations (Weems and Costa 2005; Westenberg et al. 2004). It seems important for models to consider how feedback from peers impacts upon the child's perceptions of the social world and their idea of how others perceive their social behavior. In this vein, it would be important to investigate whether negative or unsuccessful peer interactions merely serve to confirm pre-existing beliefs about one's social inadequacy or if they actually play a greater role in shaping the child's perceptions, and consequently the likelihood of developing severe social anxiety. Furthermore, from the current 
literature it is still unclear exactly why socially anxious youth are less liked than their non-anxious age peers (Verduin and Kendall 2008). One candidate is an overall lack of social skills (Miers et al. 2010), however it could be that the peers react to attractiveness, general appearance or the use of safety behaviors as opposed to basic skill deficits. Hence further research is required to tease apart the influence of these factors on peer judgments of socially anxious youth.

A new developmental model would also need to address the question of how negative perceptions, social skills and negative peer interactions influence each other in the formation of youth social anxiety. The studies reviewed here cannot inform about the order in which these factors occur and there may be several possibilities. For example, as suggested in the current review a lack of basic social skills may lead to the formation of negative social cognitions through negative feedback received by peers. In this case, the negative cognitions would be based on actual social skill inadequacies and unbiased. Alternatively, negative social cognitions may have already been passed on to the developing youth by their parents (Creswell and O'Connor 2006; Lester et al. 2010), which could increase feelings of anxiety about social situations and lead to overestimations of poor social performance. These biased cognitions may, however, in time come to reflect a kernel of truth. Negative thoughts about one's social performance and accompanying anxious feelings may hinder the youth's ability to perform skillfully in social situations. Negative peer responses to unskilled social behavior would then serve to reinforce the pre-existing negative social perceptions and enhance socially anxious feelings, in a vicious circle.

In order to disentangle the influences of poor social skills, negative cognitions, familial processes and peer feedback on the development of social anxiety in youth future studies could use a longitudinal design in which a group of children are followed from an age that temporally precedes the onset of social anxiety disorder. These different factors could be measured at predetermined and frequent intervals in order to document the formation of negative perceptions and/or social skills deficits over time. Alternatively, using cross-sectional data, structural equation modeling could test different models in which the order of social skills, negative perceptions and negative peer interactions in their influence on social anxiety are varied, and the models evaluated in terms of their fit to the data.

A point on which the two leading cognitive models differ is the role of attentional processes in the maintenance of social fear (Schultz and Heimberg 2008). Clark and Wells (1995) propose that upon entering a social situation attention is directed to the self, which prevents social phobics from perceiving information from the social environment that is inconsistent with their fear (hence, this information from the external environment is suggested to reflect positive behaviors from other people), and simultaneously enhances awareness of the feared anxiety responses. Rapee and Heimberg (1997) in contrast advocate that attentional resources are allocated both to aspects of the self and to potential external threat such as negative behaviors by audience members.

The findings presented in this review article are more in line with monitoring of both internal and external social cues as advocated by Rapee and Heimberg (1997). In Miers et al. (2010) unfamiliar age peers readily perceived inadequacies in the social skills of high socially anxious adolescents. This finding and the work of others (e.g., Blöte et al. 2007; Siegel et al. 2009) suggests that, contrary to Clark and Wells' (1995) theory, attention to the external environment would often confirm socially anxious youth's fear of negative responses from others. It therefore seems likely that socially anxious youth attend to information in the social environment, particularly from their age peers, and that this information plays a role in the formation of socially anxious youth's negative social cognitions.

In relation to socially anxious youth's negative perceptions of how nervous they look the cognitive models also propose that socially anxious individuals distort and exaggerate their physiological symptoms of arousal during social situations. Clark and Wells' (1995) model states that during social situations somatic changes occur and that these changes are interpreted as evidence of danger and anxiety. For example, an increased heart rate is perceived as losing control. For Rapee and Heimberg (1997) information from the autonomic nervous system feeds into the mental representation and this may be depicted as visible, for example a slight warm feeling in the cheeks would be represented as obvious blushing (Voncken and Bögels 2009). Because physical symptoms of arousal are seen as key candidates for negative evaluation (e.g., sweating, heart pounding) the socially anxious person will overestimate these symptoms. Hence, the cognitive models assume that socially anxious persons also perceive their arousal in perhaps a rather negative manner, and distort the degree to which they actually experience physiological symptoms.

A number of studies conducted with adult samples (e.g., Mauss et al. 2004) and one study with high and low socially anxious adolescents (Anderson and Hope 2009) indicate that socially anxious persons' perception of arousal during an anxiety evoking social task indeed does not match their actual symptoms, that is, subjective and objective physiological arousal do not correspond. This suggests that perceptions of physiological arousal are not based on truth; however, this should be replicated in youth populations. One reason for exaggerating their physiological responses is the use of self-monitoring processes by socially anxious persons (Clark and Wells 1995; Rapee and Heimberg 1997). The 
cognitive models describe how socially anxious individuals monitor different types of internal information, such as thoughts, somatic responses and images when under the threat of negative social evaluation. Future research should investigate whether high socially anxious persons' perception of physiological arousal is influenced by these increased self-monitoring processes rather than the actual physiological changes that take place.

Finally, it is recommended that research into socially anxious youth's perceptions of social situations be sure to include the perceptions of persons relevant to the anxious youth's daily social environment. Inherent to the social environment are parents and family members, and other influential adults such as a teacher or mentor. However, because of the nature of peer relationships and their increasing importance during the adolescent period (Brown 2004; Hartup 1996) it is crucial that age peers are included in research (Verduin and Kendall 2008). How age peers perceive (Miers et al. 2010), and react to (Blöte et al. 2007; Spence et al. 1999), socially anxious youth is very likely to be critical to understanding the youth's social context and the etiology and maintenance of their own perceptions of the social context. Indeed, evaluations from age peers are particularly relevant to the question of whether socially anxious youth's negative social cognitions reflect a distorted reality or a kernel of truth.

Open Access This article is distributed under the terms of the Creative Commons Attribution Noncommercial License which permits any noncommercial use, distribution, and reproduction in any medium, provided the original author(s) and source are credited.

\section{References}

Alden, L. E., \& Wallace, S. T. (1995). Social phobia and social appraisal in successful and unsuccessful social interactions. Behaviour Research and Therapy, 33, 497-505.

Alfano, C. A., Beidel, D. C., \& Turner, S. M. (2008). Negative selfimagery among adolescents with social phobia: A test of an adult model of the disorder. Journal of Clinical Child and Adolescent Psychology, 37, 327-336.

Amir, N., Beard, C., \& Bower, E. (2005). Interpretation bias and social anxiety. Cognitive Therapy and Research, 29, 433-443.

Amir, N., Foa, E. B., \& Coles, M. E. (1998). Negative interpretation bias in social phobia. Behaviour Research and Therapy, 36, 945-957.

Anderson, E. R., \& Hope, D. A. (2009). The relationship among social phobia, objective and perceived physiological reactivity, and anxiety sensitivity in an adolescent population. Journal of Anxiety Disorders, 23, 18-26.

Baker, S. R., \& Edelmann, R. J. (2002). Is social phobia related to a lack of social skills? Duration of skill-related behaviours and ratings of behavioural adequacy. British Journal of Clinical Psychology, 41, 243-257.

Barrett, P. M., Rapee, R. M., Dadds, M. M., \& Ryan, S. M. (1996). Family enhancement of cognitive style in anxious and aggressive children. Journal of Abnormal Child Psychology, 24, 187-203.
Blöte, A. W., Duvekot, J., Schalk, R. D. F., Tuinenburg, E. M., \& Westenberg, P. M. (2009). Nervousness and performance characteristics as predictors of peer behavior towards socially anxious adolescents. Journal of Youth and Adolescence. doi: 10.1007/s10964-009-9463-3.

Blöte, A. W., Kint, M. J. W., \& Westenberg, P. M. (2007). Peer behavior toward socially anxious adolescents: Classroom observations. Behaviour Research and Therapy, 45, 2773-2779.

Bögels, S. M., Snieder, N., \& Kindt, M. (2003). Specificity of dysfunctional thinking in children with symptoms of social anxiety, separation anxiety and generalized anxiety. Behaviour Change, 20, 160-169.

Bögels, S. M., \& Zigterman, D. (2000). Dysfunctional cognitions in children with social phobia, separation anxiety disorder, and generalized anxiety disorder. Journal of Abnormal Child Psychology, 28, 205-211.

Brown, B. (2004). Adolescents' relationships with peers. In R. Lerner \& L. Steinberg (Eds.), Handbook of adolescent psychology (2nd ed., pp. 363-394). New York: Wiley.

Cartwright-Hatton, S., Hodges, L., \& Porter, J. (2003). Social anxiety in childhood: The relationship with self and observer rated social skills. Journal of Child Psychology and Psychiatry, 44, 737-742.

Cartwright-Hatton, S., Tschernitz, N., \& Gomersall, H. (2005). Social anxiety in children: Social skills deficit, or cognitive distortion? Behaviour Research and Therapy, 43, 131-141.

Chorpita, B. F., Albano, A. M., \& Barlow, D. H. (1996). Cognitive processing in children: Relation to anxiety and family influences. Journal of Clinical Child Psychology, 25, 170-176.

Clark, D. M., Salkovskis, P. M., Breitholz, E., Westling, B. E., Ost, L. G., Koehler, K. A., et al. (1997). Misinterpretation of bodily sensations in panic disorder. Journal of Consulting and Clinical Psychology, 65, 203-213.

Clark, D. M., \& Wells, A. (1995). A cognitive model of social phobia. In R. G. Heimberg, M. R. Liebowitz, D. A. Hope, \& F. R. Schneier (Eds.), Social phobia: Diagnosis, assessment, and treatment (pp. 69-93). New York: Guilford Press.

Constans, J. I., Penn, D. L., Ihen, G. H., \& Hope, D. A. (1999). Interpretive biases for ambiguous stimuli in social anxiety. Behaviour Research and Therapy, 37, 643-651.

Creswell, C., \& O'Connor, T. G. (2006). 'Anxious cognitions' in children: An exploration of associations and mediators. British Journal of Developmental Psychology, 24, 761-766.

Creswell, C., Schniering, C. A., \& Rapee, R. M. (2005). Threat interpretation in anxious children and their mothers: Comparison with nonclinical children and the effects of treatment. Behaviour Research and Therapy, 43, 1375-1381.

Erath, S. A., Flanagan, K. S., \& Bierman, K. L. (2007). Social anxiety and peer relations in early adolescence: Behavioral and cognitive factors. Journal of Abnormal Child Psychology, 35, 405-416.

Franklin, M. E., Huppert, J., Langner, R., Leiberg, S., \& Foa, E. B. (2005). Interpretation bias: A comparison of treated social phobics, untreated social phobics, and controls. Cognitive Therapy and Research, 29, 289-300.

Gazelle, H., \& Ladd, G. W. (2003). Anxious solitude and peer exclusion: A diathesis-stress model of internalizing trajectories in childhood. Child Development, 74, 257-278.

Greco, L. A., \& Morris, T. L. (2005). Factors influencing the link between social anxiety and peer acceptance: Contributions of social skills and close friendships during middle childhood. Behavior Therapy, 36, 197-205.

Hartup, W. W. (1996). The company they keep: Friendships and their developmental significance. Child Development, 67, 1-13.

Heinrichs, N., \& Hofmann, S. G. (2001). Information processing in social phobia: A critical review. Clinical Psychology Review, 21, 751-770. 
Huppert, J. D., Foa, E. B., Furr, J. M., Filip, J. C., \& Mathews, A. (2003). Interpretation bias in social anxiety: A dimensional perspective. Cognitive Therapy and Research, 27, 569-577.

Huppert, J. D., Pasupuleti, R. V., Foa, E. B., \& Mathews, A. (2007). Interpretation biases in social anxiety: Response generation, response selection, and self-appraisals. Behaviour Research and Therapy, 45, 1501-1515.

Inderbitzen-Nolan, H. M., Anderson, E. R., \& Johnson, H. S. (2007). Subjective versus objective behavioral ratings following two analogue tasks: A comparison of socially phobic and nonanxious adolescents. Journal of Anxiety Disorders, 21, 76-90.

Kovacs, M. K. (1992). Children's depression inventory-Short form (CDI). New York: Multi-Health Systems Inc.

La Greca, A. M., \& Lopez, N. (1998). Social anxiety among adolescents: Linkages with peer relations and friendships. Journal of Abnormal Child Psychology, 26, 83-94.

La Greca, A. M., \& Prinstein, M. J. (1999). The peer group. In W. K. Silverman \& T. H. Ollendick (Eds.), Developmental issues in the clinical treatment of children and adolescents (pp. 171-198). Needham Heights, MA: Allyn and Bacon.

Lester, K. J., Seal, K., Nightingale, Z. C., \& Field, A. P. (2010). Are children's own interpretations of ambiguous situations based on how they perceive their mothers have interpreted ambiguous situations for them in the past? Journal of Anxiety Disorders, 24I, 102-108.

Mauss, I. B., Wilhelm, F. H., \& Gross, J. J. (2004). Is there less to social anxiety than meets the eye? Cognition and Emotion, 18, 631-662.

Micco, J. A., \& Ehrenreich, J. T. (2008). Children's interpretation and avoidant response biases in response to non-salient and salient situations: Relationships with mothers' threat perception and coping expectations. Journal of Anxiety Disorders, 22, 371-385.

Miers, A. C., Blöte, A. W., Bögels, S. M., \& Westenberg, P. M. (2008). Interpretation bias and social anxiety in adolescents. Journal of Anxiety Disorders, 22, 1462-1471.

Miers, A. C., Blöte, A. W., Bokhorst, C. L., \& Westenberg, P. M. (2009). Negative self-evaluations and the relation to performance level in socially anxious children and adolescents. Behaviour Research and Therapy, 47, 1043-1049.

Miers, A. C., Blöte, A. W., \& Westenberg, P. M. (2010). Peer perceptions of social skills in socially anxious and nonanxious adolescents. Journal of Abnormal Child Psychology, 38, 33-41.

Morgan, J., \& Banerjee, R. (2006). Social anxiety and self-evaluation of social performance in a nonclinical sample of children. Journal of Clinical Child and Adolescent Psychology, 35, 292-301.

Muris, P. (2010). Anxiety-related reasoning biases in children and adolescents. In J. A. Hadwin \& A. P. Field (Eds.), Information processing biases and anxiety (pp. 21-45). Chichester, UK: Wiley-Blackwell.

Muris, P., Merckelbach, H., \& Damsma, E. (2000). Threat perception bias in nonreferred, socially anxious children. Journal of Clinical Child Psychology, 29, 348-359.

Muris, P., Rapee, R., Meesters, C., Schouten, E., \& Geers, M. (2003). Threat perception abnormalities in children: The role of anxiety disorders symptoms, chronic anxiety, and state anxiety. Journal of Anxiety Disorders, 17, 271-287.

Norton, P. J., \& Hope, D. A. (2001). Kernels of truth or distorted perceptions: Self and observer ratings of social anxiety and performance. Behavior Therapy, 32, 765-786.

Rapee, R. M., \& Heimberg, R. G. (1997). A cognitive-behavioral model of anxiety in social phobia. Behaviour Research and Therapy, 35, 741-756.

Rapee, R. M., \& Spence, S. H. (2004). The etiology of social phobia: Empirical evidence and an initial model. Clinical Psychology Review, 24, 737-767.
Rodebaugh, T. L., \& Rapee, R. M. (2005). Those who think they look worst respond best: Self-observer discrepancy predicts response to video feedback following a speech task. Cognitive Therapy and Research, 29, 705-715.

Schneider, B. H. (2009). An observational study of the interactions of socially withdrawn/anxious early adolescents and their friends. Journal of Child Psychology and Psychiatry, 50, 799-806.

Schultz, L. T., \& Heimberg, R. G. (2008). Attentional focus in social anxiety disorder: Potential for interactive processes. Clinical Psychology Review, 28, 1206-1221.

Siegel, R. S., La Greca, A. M., \& Harrison, H. M. (2009). Peer victimization and social anxiety in adolescents: Prospective and reciprocal relationships. Journal of Youth and Adolescence, 38, 1096-1109.

Spence, S. H., Donovan, C., \& Brechman-Toussaint, M. (1999). Social skills, social outcomes, and cognitive features of childhood social phobia. Journal of Abnormal Psychology, 108, 211-221.

Stopa, L., \& Clark, D. M. (2000). Social phobia and interpretation of social events. Behaviour Research and Therapy, 38, 273-283.

Vassilopoulos, S. P., \& Banerjee, R. (2008). Interpretation and judgments regarding positive and negative social scenarios in childhood social anxiety. Behaviour Research and Therapy, 46, 870-876.

Vassilopoulos, S. P., Banerjee, R., \& Prantzalou, C. (2009). Experimental modification of interpretation bias in socially anxious children: Changes in interpretation, anticipated interpersonal anxiety, and social anxiety symptoms. Behaviour Research and Therapy, 47, 1085-1089.

Verduin, T. L., \& Kendall, P. C. (2008). Peer perceptions and liking of children with anxiety disorders. Journal of Abnormal Child Psychology, 36, 459-469.

Voncken, M. J., Alden, L. E., \& Bögels, S. M. (2006). Hiding anxiety versus acknowledgment of anxiety in social interaction: Relationship with social anxiety. Behaviour Research and Therapy, 44, 1673-1679.

Voncken, M. J., \& Bögels, S. M. (2009). Physiological blushing in social anxiety disorder patients with and without blushing complaints: Two subtypes? Biological Psychology, 81, 86-94.

Voncken, M. J., Bögels, S. M., \& de Vries, K. (2003). Interpretation and judgmental biases in social phobia. Behaviour Research and Therapy, 41, 1481-1488.

Voncken, M. J., Bögels, S. M., \& Peeters, F. (2007). Specificity of interpretation and judgemental biases in social phobia and depression. Psychology and Psychotherapy: Theory, Research and Practice, 80, 443-453.

Watson, D., Clark, L. A., \& Tellegen, A. (1988). Development and validation of brief measure of positive and negative affect: The PANAS scales. Journal of Personality and Social Psychology, 54, 1063-1070.

Weems, C. F., \& Costa, N. M. (2005). Developmental differences in the expression of childhood anxiety symptoms and fears. Journal of the American Academy of Child and Adolescent Psychiatry, 44, 656-663.

Westenberg, P. M., Bokhorst, C. L., Miers, A. C., Sumter, S. R., Kallen, V. L., van Pelt, J., et al. (2009). A prepared speech in front of a pre-recorded audience: Subjective, physiological and neuroendocrine responses to the Leiden Public Speaking Task. Biological Psychology, 82, 116-124.

Westenberg, P. M., Drewes, M. J., Goedhart, A. W., Siebelink, B. M., \& Treffers, P. D. A. (2004). A developmental analysis of selfreported fears in late childhood through mid-adolescence: Social-evaluative fears on the rise? Journal of Child Psychology and Psychiatry, 45, 481-495.

Wilson, J. K., \& Rapee, R. M. (2005). Interpretative biases in social phobia: Content specificity and the effects of depression. Cognitive Therapy and Research, 29, 315-331. 